\title{
Indiscriminability and the Phenomenal
}

\section{Citation}

Siegel, Susanna. 2004. Indiscriminability and the phenomenal. Philosophical Studies 120, nos. 1-3: 91-112.

\section{Published Version}

http://dx.doi.org/10.1023/B:PHIL.0000033752.70521.13

\section{Permanent link}

http://nrs.harvard.edu/urn-3:HUL.InstRepos:3164348

\section{Terms of Use}

This article was downloaded from Harvard University's DASH repository, and is made available under the terms and conditions applicable to Other Posted Material, as set forth at http:// nrs.harvard.edu/urn-3:HUL.InstRepos:dash.current.terms-of-use\#LAA

\section{Share Your Story}

The Harvard community has made this article openly available.

Please share how this access benefits you. Submit a story.

Accessibility 


\title{
SUSANNA SIEGEL
}

\section{INDISCRIMINABILITY AND THE PHENOMENAL}

\author{
In Philosophical Studies volume 120, 90-112
}

In "The Limits of Self-Awareness" (this volume) , M.G.F. Martin characterizes disjunctivism about perceptual experience as follows:

[S]tatements about how things appear to a perceiver [are] equivalent to statements of a disjunction that either one is perceiving such and such or one is suffering an illusion (or hallucination) ... such statements are not to be viewed as introducing a report of a distinctive mental event or state common to these various disjoint situations. (p. 1)

The disjunctive theory stands opposed to the common-kind theory, according to which there are pairs of genuine perceptions and mere seemings to perceive that have some fundamental kind of mental state in common.

The issue between disjunctivism and the common-kind theory concerns the status of being indiscriminable from a veridical perception. Suppose, for example, that I see a green cube, and my experience is veridical - no illusion is involved. An example of the sort of indiscriminability property whose status is at issue is the property of being indiscriminable from my experience of seeing the green cube.'

As Martin sees it, the common-kind theorist and the disjunctivist have three bones of contention. First, the common-kind theorist affirms, while the disjunctivist denies, that for any event indiscriminable from a (specific) veridical perception, there is a robust property in virtue of which that event is so indiscriminable. According to the common-kind theory, once we fix on an indiscriminability property - for instance, the property of being indiscriminable from my seeing the green cube - any event that has this property has it in virtue of having some robust property or other, so the indiscriminability property isn't fundamental. This brings us to the second bone of contention. As Martin characterizes it, the common-kind theory goes further than merely denying that indiscrminability from veridical perception is a brute fact: in addition, any two events with the same (specific) indiscriminability property have it in virtue of having the same (specific) robust property. This entails that there is a common kind: a kind that hallucinations and perceptions share.

In contrast, Martin denies that there is any fundamental kind to which hallucinations and perceptions both belong. According to Martin's version of disjunctivism, some experiences - but only some - are indiscriminable from a (specific) veridical perception, even when there is no robust property they have in virtue of which they are so indiscriminable. This is Martin's line on causally matching hallucinations: hallucinations with the same proximate causal antecedents as veridical perceptions. Such hallucinations, Martin holds, belong to the fundamental kind: being indiscriminable from a veridical perception. Other experiences, Martin thinks, belong to this kind, but it is not their fundamental kind. Veridical perceptions are, naturally, 
indiscriminable from veridical perceptions; but they are so indiscriminable, Martin thinks, in virtue of having robust properties. My veridical perception of the green cube, for instance, Martin thinks, is indiscriminable from a veridical perception of the green cube in virtue of the perceptual relation that holds between the perceiver (me), on the one hand, and the cube and the properties of it that appear to me, on the other. Veridical perceptions belong to the fundamental kind: being veridical perceptions; whereas causally matching hallucinations belong to the fundamental kind: being indiscriminable from a veridical perception.

So Martin agrees with the common-kind theorist that there is a common element between causally-matching hallucinations and the veridical perceptions they causally match; ${ }^{2}$ but disagrees about the depth and significance of the commonality. For Martin, it goes no deeper than the indiscriminability property, and it does not constitute the fundamental kind to which both experiences belong. ${ }^{3}$ So far, I've mentioned two of the three bones of contention between the Martin's disjunctivism and the common-kind theory. The first was that the disjunctivist (of Martin's stripe) ${ }^{4}$ allows, while the common-kind theorist denies, that being indiscriminable from a (specific) veridical perception can be a brute fact. The second is that the common-kind theorist allows, while the disjunctivist denies, that for any paired hallucination and perception that (in some intuitive sense) seem the same to the subject, there is a single mental state had by both experiences that constitutes their fundamental kind. The third disagreement concerns the concept of perceptual experience. Martin takes indiscriminability from veridical perception to be definitive of perceptual experience: "being indiscriminable from veridical perception," he writes, "is the most inclusive conception we have of what sensory experience is" (p. 22). Now, Martin takes it that the common-kind theorist will agree that for an event to so much as count as a perceptual experience, it has to be indiscriminable from a veridical perception. So they will agree, Martin thinks, that it's a conceptual truth that sensory experiences are indiscriminable from veridical perceptions. The disagreement is supposed to concern whether anything else is conceptually true of sensory experience. As Martin construes his opponent, she says that something else is: it is part of the concept of perceptual experiences that they instantiate mental properties that realize, or underlie, indiscriminability from veridical perception. As to the metaphysical nature of the common kind property, there are the options made familiar by the history of the philosophy perception so far: candidates include sense-data, being an adverbial modification, having propositional content of some sort, and combinations thereof.

In what follows, I will challenge both the assumption that phenomenality and indiscriminability from veridical perception are as closely linked as Martin thinks they are, and Martin's defense of disjunctivism. Sections 1 and 2 criticize Martin's claim that every experience is indiscriminable from a veridical perception: section 1 focuses on veridicality; section 2 on indiscriminability. In section 3 , I turn to Martin's argument against the common-kind theory, which is supposed to motivate taking the disjunctivist conception of experience as the default. In section 4 I address a residual question related to the apparent intransitivity of looking the same with respect to hue. 
I conclude the discussion in section $5 .^{5}$

1. VERIDICALITY

Both Martin's disjunctivism and the common-kind theory, as Martin understands it, are supposed to endorse a strong link between the

notions of phenomenality and indiscriminability from a veridical

perception. More exactly, both positions are supposed to agree that

any event that counts as a perceptual experience is indiscriminable

from a veridical perception.

One might question the claim that the phenomenal is quite

as closely linked to indiscriminability from veridical perception

as Martin suggests. Consider, for example, a virtual-reality scene

made to look just like what's depicted in Escher's drawing of

the impossible staircase. There seems to be no possible veridical

perception from which an experience of seeing such a scene is indiscriminable. Yet it seems to be a perfectly good specimen of a perceptual experience. ${ }^{6}$

A different sort of example casts additional doubt on the claim that any event that counts as a perceptual experience is indiscriminable from a veridical perception. Suppose the following sort of error theory of color is correct: visual experience represents color properties, but nothing external is, or could in principle be colored. ${ }^{7}$

On this view, when earlier I described my experience by saying that

I saw a green cube, strictly speaking this was a misdescription: what

I saw was a cube, and though it appeared green, there was no color

property had by the cube that my experience even so much as falsely

represented.

If such an error theory were correct, then there would not be any

veridical perception from which my experience of seeing the green appearing cube is indiscriminable. Many philosophers would find

such a theory implausible. ${ }^{8}$ But presumably its implausibility has

nothing to do with miscategorizing the event of seeing the greenappearing

cube as an experience. Like the events of seeing Escher

drawing, this event seems a fine specimen of an experience; and,

crucially, its status as fine specimen seems independent of whether

the error theory described is correct.

I've been questioning the claim that any event that counts

as a perceptual experience is indiscriminable from a veridical

perception. As we've seen, Martin's disjunctivism includes an

even stronger claim connecting phenomenality to indiscriminability, a claim concerning

the very concept of perceptual experiences:

In fixing on our concept of perceptual experience, we seem to have no more resources than we need to pick out something indiscriminable from a veridical perception. (p. 11)

Martin considers it a conceptual truth about perceptual experiences that they are indiscriminable from veridical perception. If this were right, then error theorists of color would be conceptually confused about what experience is. But whatever errors such theorists may be making, they do not seem to include conceptual confusion about what to count as an experience.

2. INDISCRIMINABILITY

So far, I've criticized the idea that phenomenality is linked 
to indiscriminability from veridical perception. I now want to challenge the idea that it is linked to any notion of indiscriminability. As Martin thinks of it, indiscriminability is a notion defined in terms of judgment. "To discriminate two things," Martin writes, "is judge them non-identical" (p. 26). This suggests that when A and B are indiscriminable for a subject, the subject cannot tell them apart in judgment. Saying no more than this leaves much unsettled about what indiscriminability is, and shortly we will consider two ways to precisify the notion. For the moment, what's notable is that Martin's notions of discriminability and indiscriminability are cognitive notions. As we saw earlier, Martin takes the common-kind theorist to be committed to the claim that any event that counts as a perceptual experience is indiscriminable from a veridical perception..$^{10}$ Let $\mathrm{S}$ be a subject, and let $I^{*}$ be a robust property of the sort that, by the lights of the common-kind theory, is supposed to bestow on any event that has it the property of being indiscriminable from a veridical perception. So fix on an indiscriminability property, such as the property of my seeing the green cube, and by the lights of the common-kind theory (as Martin construes it) there is a property $I^{*}$ that characterizes what it is like to have an experience with that indiscriminability property. In the hands of Martin's common-kind theorist, then, $\mathrm{I}^{*}$ is supposed to play two roles: first, it is supposed to make any event that has it indiscriminable from a veridical perception; second, it is supposed to characterize what the experience islike for the subject. Martin, then, takes his opponent to accept the following:

Sufficiency claim: If S's experience has I*, then S's experience is indiscriminable from a veridical perception.

What the Sufficiency claim comes to depends on how the notion of indiscriminability is understood. I will now consider two notions of indiscriminability, and argue that on each way, someone sympathetic to the main thrust of the common-kind theory could reasonably deny the Sufficiency claim - though for different reasons each time. Both doubts come into focus by considering creatures who have perceptual experiences, yet lack the cognitive resources to make judgments about them. In addition, as we will see, the possibility of this sort of creature also threatens Martin's positive view that two events' being indiscriminable from the same veridical perception suffices for their being phenomenally the same. I'll call the first notion of indiscriminability the positive notion: ${ }^{11}$

Positive: $\mathrm{X}$ is indiscriminable from $\mathrm{Y}$ by a subject $\mathrm{S}$ at time $\mathrm{t}$ iff $\mathrm{S}$ is disposed to judge on basis $\mathrm{b}$ that $\mathrm{X}=\mathrm{Y}$.

This notion of indiscriminability has a parameter for the basis of S's disposition to judge. The motivation for having such a parameter is as follows. Suppose that X and Y look totally different to S, but S is disposed to judge on the basis of consulting an unreliable oracle that $\mathrm{X}=\mathrm{Y}$. Without the parameter for the basis, by the positive notion, $\mathrm{X}$ and $\mathrm{Y}$ would count as indiscriminable for $\mathrm{S}$. This seems like the wrong result. In any case, it seems clear that the basis Martin has in mind is "introspection and reflection", ${ }^{12}$ so let us put that in for $b$. 
Now, suppose there were a creature who had I*, but who was not equipped to form any judgments at all, ergo was not disposed to judge that she was veridically perceiving. On the positive account of indiscriminability, the sufficiency claim would predict that if such a creature had a perceptual experience, then $S$ would be disposed to judge on the basis of introspection and reflection that S's experience is a veridical perception. For the sort of creature imagined, this prediction would be false.

Martin's construal of the common-kind theory, then, would be too restrictive, given the positive notion of indiscriminability. The existence of creatures who have perceptual experiences without capacities for judgment is compatible with there being pairs of veridical perception and causally-matching hallucination that share a common mental kind. So rejecting the Sufficiency claim does not seem tantamount to giving up on the central claim of the common-kind theory itself.

I've complained that Martin shouldn't attribute the Sufficiency claim to the common-kind theorist. In my complaint, I've assumed that if some sort of first-person access to what experiences are like is required, this access can take a form other than judgment. It is a difficult question how to understand the nature of such access, once it's stipulated not to involve judgment. Perhaps there is a more primitive form of introspective access of some sort.

The same sort of creature presents a different reason for a common-kind theorist to deny the Sufficiency claim, when that claim is taken to involve indiscriminability understood differently. I'll call the second notion of indiscriminability, which is proposed by TimothyWilliamson, the double-negative notion of indiscriminability:

Double-negative: $\mathrm{X}$ is indiscriminable from $\mathrm{Y}$ by a subject $S$ at time $t$ iff $S$ is not able at $t$ to activate knowledge that $\mathrm{X}=/=\mathrm{Y} .{ }^{13}$

Using this notion of indiscriminability, the Sufficiency claim comes to this:

Sufficiency claim-TW: If S's experience has I*, then S cannot activate knowledge that having-I* is distinct from having a veridical perception.

With respect to the sort of creature lacking cognitive equipment of the sort needed to form judgments, Sufficiency claim-TW is trivial. For such a creature, there will be no pair of perceptual experiences such that the creature can activate knowledge that they are distinct from one another. So all perceptual experiences of the creature will count as indiscriminable from one another. ${ }^{14}$ This gives the common-kind theorist reason to reject the Sufficiency claim, on the grounds that it doesn't capture anything important in their view. The case of creatures with perceptual experiences who lack capacities for judgment also suggests an objection to Martin's positive view that being indiscriminable from the same veridical perception is sufficient for two events' being phenomenally the same. Assuming either notion of indiscriminability, all of the experiences of such creatures will count as the same, if indiscriminability 
suffices for sameness of experience.

Martin considers and responds to this very worry. His response is that the relevant notion of discriminability is impersonal:

when we turn to the experiences of sentient but unselfconscious creatures, to the extent that we do have a positive grip on the kinds of experience that they can have, and which can differ one from another, we also have a grip on how such experience would be discriminable through reflection or not ... a dog might fail to discriminate one experience from another, making no judgment about them as identical or distinct at all, [but] that is not to say that we cannot judge, in ascribing them such experience, that there is an event which would or would not be judgably different from another experience. (p. 28)

If the claim here is that two of the dog's experiences are discriminable by someone other than the dog, that seems correct. But it does not seem correct to say that they are discriminable by reflection, if reflection is supposed to be on the part of the subject whose states are in question. After all, by hypothesis it is not the dog doing the reflecting, and it is not clear what it would be for us to reflect on the dog's experiences, without doing some empirical investigating of a sort that the dog would be incapable of carrying out. If the relevant sort of (in)discriminability is (in)discriminability for a subject on the basis of that subject's reflection and introspection, then the appeal to the impersonal notion won't work in this case..$^{15}$

On another reading, Martin's response to the worry is that there is a sense in which some of the dog's experiences are discriminable from one another, to the dog. But the notion of discriminability that would make this claim true could not be a cognitive notion. And as we've seen, it is a cognitive notion that is at work in Martin's central claims.

\section{MARTIN'S OBJECTION TO THE COMMON-KIND THEORY}

So far, I've been criticizing Martin's views of the relation between indiscriminability and the phenomenal. These views form the background to his argument for disjunctivism. I now want to turn to that argument itself.

Martin's defense of disjunctivism aims to show that the disjunctivist conception of perceptual experience should be the default conception. It should be the default conception, Martin thinks, because otherwise one's epistemological assumptions about the mind will be very weighty. ${ }^{16}$ The fact (as Martin sees it) that the common-kind theory is committed to such weighty epistemic assumptions is the main objection he raises against that theory. This fact, in turn, is the main reason given for why the disjunctivist conception should be the default. I will now examine this objection. Martin gives the objection in a passage that contrasts the supposed "modesty" of disjunctivism with the supposed "immodesty" of the common-kind theory. Disjunctivism is supposed to be modest, because it takes indiscriminability from a veridical perception as necessary and sufficient for an event to count as an experience. The common-kind theory, in contrast, is supposed to be immodest, because it takes as necessary and sufficient for an event to be an experience that it instantiate a robust property that realizes the indiscriminability from a veridical perception. In the first part of the objection, Martin considers how the common-kind view would 
classify a situation in which a subject was unable to discriminate her situation from one in which she was seeing a street scene, and yet had no robust property of the sort that the common-kind theory takes to characterize perceptual experience:

For the immodest view in question this could not be a case of visual experience as of a street scene, while by modest lights that would be exactly what it is.... Now surely this result would surely be unfortunate for any immodest view, given our initial assumptions. For we supposed that reflection on experience offers support to a naïve realist construal of sensory experience. When one reflects on one's experience it seems to one as if one is thereby presented with some experience-independent elements of the scene before one as constituents of one's experience and not merely as represented to one as in imagination. (p. 10)

There seem to be two steps here that Martin thinks the common kind theorist is forced to take. The first step is that an event is indiscriminable from a veridical perception, just in case it seems to the subject as if she is "presented with experience-independent elements of the scene before her as constituents of her experience". This is supposed to be an upshot of the initial assumption that reflection on experience supports a naïve realist construal of experience. The second step is that it seems to one as if one is presented with such elements, just in case one is having a perceptual experience (perhaps a hallucinatory one). And this seems plausible. Putting these steps together, being indiscriminable from veridical perception suffices for being an experience. As we've seen, Martin also thinks there are grounds (acceptable to disjunctivist and non-disjunctivist alike) for the converse - that all experiences are indiscriminable from a veridical perception. I raised some worries about that earlier, but let us set them aside here. Combining these commitments gives us

(1) I iff E,

where ' $I$ ' is for indiscriminability from a veridical perception, and ' $E$ ' is for being a perceptual experience, and (1) abbreviates "all and only the events indiscriminable from veridical perceptions are experiences."

This brings us to the second part of the objection:

A proponent of the immodest view can only hope to offer necessary as well as sufficient conditions for having an experience - and hence to explain the having of an experience in terms of its favored conditions - if it can ensure that themodest approach and its favored form of immodesty coincide in the extension they give the concept of experience. (p. 11)

Here the relevant part of the sentence is the first part, with its assumption that the common-kind theorist aims to give necessary as well as sufficient conditions for having an experience. The common kind theory, recall, takes it to be a conceptual truth about perceptual experience that such experiences have a certain robust property (the exact metaphysical nature of the property is left open - it could the property of having sense-data, or of having propositional contents of sort, some combination, etc.)Where this property is R (for 'robust'), the assumption comes to this: 
(2) E iff R,

or more exactly, all and only the experiences have robust property

$\mathrm{R}$.

In the passage quoted, Martin suggests that the common-kind

theorist can accept (2) only if she accepts (3):

\section{(3) I iff R,}

that is, all and only the events indiscriminable from veridical perceptions

have the property R. In embracing (1)-(3), the common-kind

theorist ensures that it classifies as experiences all the same events

as the disjunctivism-a-la-Martin does: as Martin puts it, she ensures

that the modest and immodest approaches "coincide in the extension

they give the concept of experience."

The final part of the objection connects (1)-(3) to a substantive epistemic principle:

A proponent of the immodest view can only hope to offer necessary as well as sufficient conditions for having an experience - and hence to explain the having of an experience in terms of its favored conditions - if it can ensure that the modest approach and its favored form of immodesty coincide in the extension they give the concept of experience. In turn, this coincidence of extension can by guaranteed only if the proponent of the immodest account embraces a substantive epistemic principle... one must assume that a subject couldn't but be in a position to discriminate a situation which lacked E1 ... EN from one which possessed them.... A responsible subject who wishes to determine how things are with him or herself through reflection must be, on this view, infallible in the answers they come up with. They must not only correctly identify phenomenal properties of a specific sort when they are present, but also they cannot be misled into judging them present when they are not. (p. 11)

It is the common-kind theorist's commitment to (1)-(3) that supposedly forces her to accept the substantive epistemic principle, which from now on I will call Hefty.

Hefty: A responsible subject who wishes determine how things are with him or herself through reflection must not only correctly identify phenomenal properties of a specific sort when they are present, but also they cannot be misled into judging them present when they are not.

The success of Martin's objection to the common-kind theory (and, given the dialectical context, his success in motivating disjunctivism) hangs on two things: first, whether a commitment to Hefty really does follow from (1)-(3); second, on how plausible or implausible Hefty is. I will consider the second issue first, and then return to how exactly the commitment to Hefty on the part of the common-kind theorist is supposed to arise.

In assessing the plausibility of Hefty, a crucial interpretive question is what sorts of properties E1 ... EN, the "phenomenal properties of a specific sort", are meant to be. Either they are robust properties that characterize a specific type of veridical experience, such as my seeing the green cube; or else they are the robust general properties, shared by all such specific ones, such as the property of having propositional content, or being sense-data. Call these strong and weak robust properties, respectively. Up until the statement of Hefty, it seems clear that it is weak 
robust properties are at issue: notably, premises (2) and (3) concern the property that (by the lights of the common-kind theory) is supposed to be necessary for having an experience at all. And it is surely not necessary for an event to count as a perceptual experience that it have the strong robust property (if such there be) that characterizes my veridically seeing the green cube. As pleasant as it is for me to see the green cube, it is thankfully not the only type of experience one can have. It seems undeniable that the properties at issue are the weak ones, rather than the strong ones. Martin's case against Hefty goes like this:

[T] he doctrine of infallibilism about the mental is particularly problematic in relation to sensory states once we are forced to admit that appearances. systematically appear to us other than they are. For if we can be misled with respect to some properties of sensory experiences, there is a question as to what can motivate the claim that we are infallible in other judgments about them ... part of the motivation of disjunctivism is precisely the thought that introspection of our sense experience supports Naïve Realism, and hence forces us to see both sense-datum and intentional theories as forms of error theory. (p. 12)

The idea here seems to be that Hefty does not sit well with the common-kind theory, because the common-kind theory already accepts some sort of fallibility to introspection in rejecting Naïve Realism. In rejecting Naïve Realism, the common-kind theorist denies that veridical experiences consist in part in the objects perceived. Combining this with the claim that Naïve Realism introspectively seems to be true - a claim that, as we've seen, Martin thinks the common-kind theorist should accept (see discussion of (1) above) - the result is that introspection is fallible about the metaphysical nature of perceptual experience. If the common-kind theory

is already committed to introspection delivering fallible results about the metaphysical nature of experience, the thought seems to be, then the idea that it would be infallible about some other aspect of experience seems to be undermined. ${ }^{17}$ This is Martin's reason for thinking that Hefty is implausible.

In order to assess this reason to reject Hefty, one more interpretive issue concerning Hefty needs to be settled. Hefty, recall, was the epistemic principle that "a responsible subject who wishes to determine how things are for themselves sensorily must ... not only correctly identify phenomenal properties of a specific sort when they are present, but also they cannot be misled into judging them present when they are not" (p. 10). This principle can be interpreted in two ways: extensionally or intensionally.

Taken extensionally, Hefty entails that a subject who satisfies it can discriminate on the basis of introspection between events that have the weak robust property and events that lack it. But it is not required, on the extensional interpretation of Hefty, that the subject know what sort of properties she is discriminating between. It is enough simply that she make the discriminations, on the basis of introspection, infallibly.

Taken intensionally, Hefty is much more demanding. A subject who satisfies intensional Hefty will be disposed to judge correctly that she has weak robust properties of sort R, where $\mathrm{R}$ specifies the metaphysical nature of the robust properties: e.g., sense-data, or representational properties. Intensional Hefty says, in effect, that 
introspection can reveal the basic metaphysical nature of the properties that characterize what it is like to have an experience. If intensional Hefty is true, then introspection can reveal that perceptual experience is the having of representational properties, or sense-data, or some combination - whichever (if any) of these properties perceptual experiences turn out to have.

In an earlier paper, Martin gave convincing grounds for doubting intensional Hefty. If intensional Hefty were correct, Martin has noted, it would difficult to explain how there can so much as be philosophical disagreement about the nature of experience. The disagreements philosophers have about metaphysics of experience don't seem plausibly to result from variation in their inner lives. ${ }^{18}$ It does not seem to be introspection alone that decides between, say, the sense-datum theory and the theory that experience consists entirely in representational properties. Other sorts reasoning are needed. So introspection doesn't seem to provide substantive knowledge of weak robust properties.

The reason Martin gives in the text for rejecting Hefty also counts against intensional Hefty. If the common-kind theorist embraced intensional Hefty, she would be saying, in effect, "introspection wrongly tells me that experiences partly consist in external objects that I perceive; yet it also tells me infallibly that my experience consists in weak robust property R." There is a tension here, given that $\mathrm{R}$ is by definition the sort of property that can be had by hallucinations, and so cannot be object-involving. But neither of the arguments Martin gives against Hefty work so decisively against the extensional version of Hefty. Introspection may not infallibly reveal the nature of weak robust properties (if there are such), but that's compatible with it providing infallible grounds for discriminating between events that are experiences and events that aren't. And this is also compatible with introspection being wrong - even systematically so - about the nature of weak robust properties. So for all Martin says, extensional Hefty has not been shown to be implausible, or even in tension with the commonkind theory. Being committed to extensional Hefty does not seem to be a reason to reject the common-kind theory, or to regard the disjunctivist conception of experience as the default. But what exactly is the common-kind theorist committed to? As wes saw earlier, one of the claims Martin thinks the common-kind theorist is committed to is that an event is an experience just in case it has a robust property of type $\mathrm{R}$ :

\section{(2) E iff R.}

From here, it is a simple step to Hefty, with the following assumption: subjects can infallibly discriminate between events that are experiences and events that aren't. For if a subject "couldn't but be in a position to discriminate" experiences from non-experiences, then she also "couldn't but be in a position to discriminate an situation which lacked E1 ... EN from a situation which possessed them", where E1 ...EN is a weak robust property. This is one way in which the common-kind theorist's commitment to Hefty could arise. 
It seems plausible to suppose that any common-kind theorist is indeed committed to (2), and from (2) plus the assumption about infallible discrimination of experiences from non-experiences, some version of Hefty follows. The version that follows, however, is the extensional version. That version isn't obviously implausible, and in any case Martin's arguments against Hefty, as we've seen, work only against the intensional version.

Another argument that the common-kind theorist is committed to some version of Hefty proceeds from two premises: I iff R (claim (3) above), and the transitivity of indiscriminability. The main idea is the same as above: if I and $\mathrm{R}$ are co-extensive, then infallible discrimination of events with I from events without I just is infallible discrimination of events with $\mathrm{R}$ from events without $\mathrm{R}$. And the latter just is Hefty.

Why think that subjects can infallibly discriminate events with I from events without I? Let $\mathrm{x}$ be an event that is indiscriminable from a veridical perception. Let e be an event that is discriminable from a veridical perception. Now suppose that subjects can't infallibly discriminate events with I from events without I. In particular, suppose that $\mathrm{e}$ and $\mathrm{x}$ are themselves indiscriminable. Then $\mathrm{e}$ is indiscriminable from $\mathrm{x}$, and $\mathrm{x}$ is (by definition) indiscriminable from a veridical perception. If indiscriminability is transitive, then e will be indiscriminable from a veridical perception. But by hypothesis, e was discriminable from a veridical perception. So we get a contradiction. That is another argument that the common-kind theorist is committed to Hefty. ${ }^{19}$

There seem to be two arguments suggested by Martin's text that the common-kind theorist ends up committed to Hefty. Neither argument, however, shows that the common-kind theorist is committed the intensional version of Hefty. And it's the intensional version that Martin argues against.

\section{A RESIDUAL PROBLEM}

As Martin characterizes the common-kind theory, it ought to be committed to the view that for each indiscriminability property (e.g., the property of being indiscriminable from my veridically seeing the green cube), there is a single robust mental property such that any event with the indiscriminability property has the robust mental property. Some doubt is cast on this claim by considerations related to intransitivity of some indiscriminability properties. Notably, if being indiscriminable with respect to hue is intransitive, then there is reason to reject the common-kind theory as Martin characterizes it. In this section, I discuss whether this counts in favor of disjunctivism.

Consider three red swatches that differ slightly in hue: they are, say, red38, red39 and red40. Many philosophers think that indiscriminability respect to color is an intransitive relation. Such intransitivity is supposed to be illustrated by cases of the following sort: a subject comparing the red38 swatch with the red39 swatch (at a time) cannot discriminate between their hues. The same subject comparing the red39 swatch with the red40 swatch (with the red38 swatch out of view) cannot discriminate those hues either. But the same subject comparing the red38 swatch with the red40 swatch (with the red39 swatch out of view) can discriminate the hues of 
those.

The case just described involves only three swatches, but that's not essential to what it is supposed to illustrate. What's essential is that there be discriminable hues on the outer edges of a range of indiscriminable ones. How many indiscriminable ones occupy the range is not important. If there are cases of the sort just described - and many philosophers think there are, though some disagree ${ }^{20}-$ they illustrate the intransitivity of looking the same with respect to hue.

For the sake of argument, I am going to ignore the controversy, and assume that indiscriminability with respect to hue really is intransitive. I will also assume, for simplicity, that the intransitivity shows up with just three swatches. This is empirically dubious, but makes it easier to get to the main point. ${ }^{21}$ If it turns out that indiscriminability with respect to hue isn't intransitive, then there is one less reason to reject the common-kind theory as Martin characterizes it.

It will be useful to spell out a (putative) case of intransitive indiscriminability in a bit more detail. Let I38 be the property of being indiscriminable from a veridical perception of red38, and let E38 and E40 be, respectively, an event of veridically seeing a swatch of red38 and an event of veridically seeing a swatch of red40. And finally, make the following assumptions about E38 and E40: E38 is indiscriminable from a veridical perception of red39 and red40; and E40 is indiscriminable from a veridical perception of red41 and red42. So E38 has three indiscriminability properties: I38, I39 and I40. Given these assumptions, E38 and E40 share the indiscriminability property I40. Both are indiscriminable from a veridical perception of red40. What must Martin's common-kind theorist say about the robust properties in virtue of which E38 and E40 each have I40? One version of the common-kind theory would predict that these robust properties have to be different. For by the hypothesis of intransitivity, red38 is discriminable from red40. If these shades are discriminable, then at least some common-kind theorists will want to say that the specific robust properties are too. These will include common-kind theorists who take the specific robust properties to be representational ones, so that differences in what is represented result in phenomenal differences.

This last move has a notable consequence: one and the same indiscriminability property could be had in virtue of having different specific robust properties. And this is to deny one of the claims that Martin attributed to the common-kind theory: that any two experiences sharing an indiscriminability property share the same specific robust property.

Is the view just sketched a disjunctivist view? There is a similarity with disjunctivism: both disjunctivism and the view sketched deny that any two experiences that are indiscriminable from the same veridical perception share the same robust mental property. However, there are also notable differences. Whereas the disjunctivist holds that there are pairs of hallucinations and veridical perceptions that are indiscriminable from the same veridical perception, yet are of fundamentally different kinds, the view just sketched can allow that pairs of experiences with different specific robust 
properties nevertheless are of the same fundamental kind. Both experiences have, as it might be, representational phenomenal properties, and for all the view says, they have a general fundamental kind in common.

The difference is only at the level of the specific robust properties.

So the view sketched does not seem to capture the heart of

disjunctivism. It does, however, seem to be incompatible with a

version of intensional Hefty - a version that says that introspection

infallibly reveals which specific robust properties a subject has.

But as we have seen, there are independent reasons to think that intensional versions of Hefty are wrong anyway.

\title{
5. CONCLUSION
}

I've suggested that someone could accept the main thrust of the common-kind theory, while rejecting two other claims that Martin attributes to it. The two claims are these: first, that the kind common to perception and hallucination is a property of an event in virtue of which it is indiscriminable from a veridical perception; second, that it is a property in virtue of which it is indiscriminable from anything at all (where indiscriminability is a cognitive notion). The main thrust of the common-kind theory, I suggested, is that there are pairs of hallucination and veridical perception sharing a fundamental kind of mental state, and this part of the theory survives the denial of the two claims just mentioned.

For all my complaints about the link Martin sees between indiscriminability and the phenomenal, rejecting it leaves a serious question unanswered. Even to state the debate between disjunctivism and its opponents, one needs a way to characterize the relevant pairs of perceptions and hallucinations. Only some such pairs raise the question whether they share a fundamental mental property. Which pairs are these? The claim that they are the pairs that are indiscriminable from the same veridical perception provides a simple answer. If this answer is rejected, it's not clear what to replace it with. Replacing it with some other notion of indiscriminability, or with some notion of phenomenal sameness, brings in weighty theoretical commitments at the outset - just as Martin's cognitive notion of indiscriminability does. The moral seems to be that in this debate, it is difficult to escape making theoretical commitments from the very start about the kind of access to experience that introspection provides. ${ }^{22}$

\author{
NOTES \\ 1 So "being indiscriminable from a veridical perception" should be taken to \\ mean something stronger than simply being indiscriminable from some veridical \\ perception or other. How much stronger? If I had two successive veridical experiences \\ of numerically different but qualitatively identical green cubes, would \\ the property of being indiscriminable from each be different indiscriminability \\ properties? For the purposes of this discussion, they could just as well count as \\ instances of the same property. \\ 2 Martin grants the conclusion of the Causal Argument from Hallucination (see \\ section 4), which he formulates as follows: "whatever kind of experience does \\ occur in situations like $h$ [hallucination], it is possible that such a kind of experience
}


occurs when one is veridically perceiving" (p. 12). Of course, "whatever kind ..." is restricted to exclude the kind: hallucination.

3 “... while the perceptual event is of a fundamental kind which could not occur when hallucinating, nonetheless this very same event is also of some other psychological kind or kinds which a causally matching hallucinatory event ... belongs to" (p. 17).

4 Martin's stripe of disjunctivism grants the conclusion of the Causal Argument from Hallucination (see previous note). There could be versions of disjunctivism that don't, however.

5 Before beginning the critical part of the discussion, a final expository note, and a warning. Martin's disjunctivism is officially undecided on two matters: first, it leaves unsettled whether it applies to each sensory modalities, or only to some, or only to perceptual experience in general. Second, it is unsettled on the status of illusions (where these are distinct from hallucinations) - whether they always instantiate robust properties in virtue of which they are indiscriminable from veridical perceptions or not, and if so, what sort of robust properties do this. I believe that Martin has views on both of these matters, but that they don't bear on the issues raised in his paper.

The warning: my discussion, like Martin's discussion, takes as understood the idea that a particular, unrepeatable experience could be indiscriminable from another (perhaps repeatable) event. It's not entirely clear what this means. The relevant notion of indiscriminability can't be a statistical notion, since the event said to be indiscriminable is unrepeatable. Nor can the notion be reasonably understood by considering what would happen if the subject had two simultaneous experiences, compared them, and found that they were the same in the relevant respect (as one might be able to do with two physical objects). Perhaps one could think of how the subject would regard the pair of experiences, if she had them successively; but that introduces complications about memory that seem extraneous. Nevertheless, there is some intuitive sense in which certain pairs of experiences seem the same to the subject. Such a notion is needed even to state the debate between the disjunctivist and the common-kind theorist, and that is one role that is played by Martin's notion of indiscriminability. I return to this point in section 5 .

6 Another example: consider an experience of seeing the Müller-Lyer lines. Which veridical perception is such that having an experience of these lines is indiscriminable from it? Presumably, if two lines really did differ in length, but each had the characteristic arrows drawn around them, they would look different than the lines look when they are the same length, at least given how our perceptual systems work.

In the very latest version of Martin's paper (written after these comments), Martin grants that Escher-experiences as a whole are not indiscriminable from a veridical perception, but suggests that they have constituent parts, each of which is indiscriminable from a veridical perception (p. 31). This strikes me as an ad hoc move tailored to specific example, and a retraction of a central claim.

7 Such an error theory might hold that color is a property of mental, internal objects such as sense-data, that it couldn't even in principle be a property of things external to the mind, and that color experience nevertheless represents external things as being colored.

8 One sort of worry that a materialist about the mental might press is how experience could ever get to represent color properties, if such properties were never instantiated.

9 The indefinite description "a visual perception" should be taken to mean the same as "some veridical perception or other." Cf. p. 20: "[t]he concept of perceptual experience in general is that of situations indiscriminable from veridical perception"; and the passage cited earlier from p. 22: "I argued above that being indiscriminable from veridical perception is the most inclusive conception we have of what sensory experience is." 
10 In section 3 I discuss some passages from pp. 10-11 of Martin's paper that show that he construes the common-kind theory is this way.

11 In the very latest version of Martin's paper (written after these comments), Martin makes explicit that he accepts the other notion of indiscriminability, not the positive notion (fn. 11, p. 10). To state the issue between disjunctivism and its opponents, some way is needed to characterize the similarity between the relevant experiences, and various notions of indiscriminability are candidate ways to do this. So it seems worth having the positive notion on the table.

$12 \mathrm{Cf}$. "some event is an experience of a street scene just in case it couldn't be told apart through introspection from a veridical perception of the street as the street" (p. 9); "If the condition of indiscriminability is to be met, then a situation of experience must not lack any property necessary for veridical perception the absence of which is recognisable simply through reflection" (p. 20); "if any property of a veridical perception is introspectible - i.e. is recognisagbly present in perception through reflection..." (p. 22). Although in section 9 of his paper Martin also appeals to impersonal notions of indiscriminability, which seems in tension with this; I discuss this notion briefly at the end of this section.

13 TimothyWilliamson, Identity and Discrimination (Oxford: Blackwell, 1990), p. 8. Two notable differences between the two notions are these. First, the positive notion makes use of the notion of disposition, whereas the double negative notion makes use of the notion of an ability. Second, where the positive notion defines indiscriminability in terms of judgment, Williamson's notion defines it in terms of knowledge. Interestingly, only the first of these differences seems to survive the attempt to define corresponding notions of discriminability. For suppose $\mathrm{X}$ and $\mathrm{Y}$ were discriminable by $\mathrm{S}$ at $\mathrm{t}$ just in case $\mathrm{S}$ was disposed to judge $\mathrm{X}$ distinct from $\mathrm{Y}$. Then $\mathrm{X}$ and $\mathrm{Y}$ could count as discriminable for $\mathrm{S}$ at $\mathrm{t}$, even in the case that $\mathrm{X}=\mathrm{Y}$. And this seems to stretch the notion of discriminability unacceptably far beyond the ordinary notion. If this infelicity were fixed by adding that the $\mathrm{S}$ at $\mathrm{t}$ be disposed to make a correct judgment, then it starts to look like it involves an appeal to knowledge (or something very much like it, given the link between knowledge and reliable judgment) after all. (Given the two dimensions of variation in the pair of notions of indiscriminability we've been considering, there are clearly other notions of indiscriminability that could also be considered.)

14 There may be an additional reason for the common-kind theorist to reject the link between phenomenality and indiscriminability, at least on Williamson's notion of indiscriminability. Consider once more what the sufficiency claim comes to, givenWilliamson's notion:

If $\mathrm{S}$ has $\mathrm{I}^{*}$, then $\mathrm{S}$ cannot activate knowledge that having-I* is distinct from having a veridical perception.

It is not clear why a common-kind theorist should accept this. Suppose the epistemic basis in question is supposed to be reflection, where this includes not only introspection but philosophical theorizing as well. Let us grant that if $\mathrm{S}$ has $I^{*}$, then on the basis of reflection, S cannot activate knowledge that she's not having a veridical perception. Nonetheless, if $\mathrm{S}$ is a common kind theorist, $\mathrm{S}$ will take herself to know by philosophical theorizing that having $\mathrm{I}^{*}$ is distinct from having a veridical perception, because $S$ will take herself to know that she could have I* even if she weren't veridically perceiving. So it seems that, by her lights, at least, she can activate knowledge that having $I^{*}$ is distinct from having a veridical perception.

Of course, Martin thinks that the philosophical theorizing that typically leads common-kind theorists to this conclusion is mistaken, and perhaps he's right. But if the claim is that a subject cannot activate the relevant knowledge on the basis of philosophical reflection, then it seems unmotivated to attribute the sufficiency claim to the common-kind theorist in the first place.

15 In considering this worry in the text, Martin also discusses the inattentive, hasty subject John, who treats samples of scarlet and vermillion indifferently. Intutively, his experiences of each should count as distinct; yet, as Martin points 
out, it does not seem inappropriate to say that John can't discriminate scarlet from vermillion. Martin takes the moral to be that the disjunctivist should adopt an 'impersonal' notion of indiscriminability, where this impersonal notion applies equally to the dog. I think the moral is rather that it's the notion of an ability to discriminate, rather than a disposition to discriminate, that should figure in the definitions of indiscriminability.

$16 \mathrm{Cf}$. last paragraph of Martin's section 2.

17 The same consideration that makes Hefty implausible for a common-kind theorist should make it implausible for anyone who accepts Martin's assumption that introspection supports Naïve Realism. If, as per Martin's assumption, introspection on experience tells you that it consists in part of an object that you are veridically perceiving, it will be incorrect in cases of hallucination, no matter whether disjunctivism or the common-kind theory is true. By Martin's lights, the common-kind theorist is forced to admit that appearances systematically appear to us other than they are, because no experiences are the way introspection (supposedly) says they are; the disjunctivist, in contrast, allows that some experiences are that way. Whether the disjunctivist also has to admit that appearances appear other than they are systematically depends on the extent to which experiences are not veridical. For discussion of the idea that most experiences are not veridical, see A.D. Smith, The Problem of Perception (Harvard University Press, 2002), chapter 1.

18 Cf. 'Beyond Dispute', in T. Crane and S. Patterson (eds.), The History of the Mind-Body Problem, p. 197.

19 The defense just mentioned itself has a controversial premise - the premise that indiscriminability is transitive. This has been defended by Graff (2001), but is widely thought to be shown false by cases of the sort discussed in the next section.

20 For assumptions that there are cases structured like the one described, see N. Goodman, The Structure of Appearance, 1st edn., Cambridge: Harvard University Press, 1951 and D. Armstrong, A Materialist Theory of Mind, London:

Routledge, 1968. For dissent, see D. Graff, 'Phenomenal Continuaa and the Sorites', Mind (2001); D. Raffman, 'Is Indistinguishability Non-transitive?', Philosophical Topics 28(1) (Spring 2001), pp. 153-175.

21 I take it that the heart of the controversy being ignored concerns whether the relation in question is transitive or not; simplifying assumptions about what form it takes won't change anything.

22 For helpful comments on earlier drafts, thanks to Alex Byrne and Bernard

Nickel. For extensive discussion of every issue discussed here, thanks to Maja Spener, Scott Sturgeon, and David Chalmers. Additional thanks to the last two for criticizing later drafts. Finally, many thanks are due to Mike Martin, for writing such a rich and rewarding paper, and for so many nice discussions of it before and during the 2002 Oberlin Colloquium.

Department of Philosophy

208 Emerson Hall

Harvard University

Cambridge MA 02138

USA

E-mail: ssiegel@fas.harvard.edu 